\title{
Parental Help-Seeking and the Moral Order. Notes for Policy-Makers and Parenting Practitioners on 'the First Port of Call' and 'No One to Turn To'
}

\author{
by Karen Broadhurst \\ Lancaster University \\ Sociological Research Online 12(6)4 \\ <http://www. socresonline.org.uk/12/6/4.html> \\ doi:10.5153/sro. 1640
}

Received: 25 May 2007 Accepted: 18 Oct 2007 Published: 30 Nov 2007

\begin{abstract}
The topic 'help-seeking' is of international interest. However, there is only a very limited literature concerning help-seeking in child welfare and a distinct dearth of studies that have examined the social organisation of parents' decisions to seek help. Recent developments in child welfare services in England and Wales have seen the introduction of a raft of initiatives that aim to deliver parenting support to a broader range of parents; however, these initiatives are not well grounded in an evidence base concerning parental help-seeking. Focusing on the organisation of talk-in-interaction in interviews and focus groups, this study examined parents' normative and inter-subjective understandings about help-seeking. The study found that when considering the welfare problems of parenting (variously described as 'domestic', 'normal' or 'on the home front'), participants routinely made relevant the binary 'inside/outside' the family, indicating the central (normative) relevance of the category 'family' for this kind of support. Outside (professional) help was very much a residual option, only to be considered on the basis of 'no-one to turn to'. The findings are discussed in relation to national strategies that seek to normalise support for parenting and issues of international relevance to do with professional identification and diagnosis of need.
\end{abstract}

\section{Keywords: Ethnomethodology, Membership Categorisation Analysis, Normativity/Social Organisation, Parenting Support}

\section{Introduction}

1.1 Whilst help-seeking is a topic of international interest, there is only a limited literature that concerns parents' help-seeking behaviour in the context of child welfare (Redmond et al. 2002; Broadhurst, 2003; Edward and Gillies, 2004). In particular, there is a significant dearth of studies that have examined the social organisation of decisions to seek help with respect to the parenting task. Focusing on talk-ininteraction and drawing on the much neglected work of Harvey Sacks Search for Help (1966), this study demonstrates how the methods of membership categorisation analysis can provide a way of examining parents' cultural or normative expectations with respect to help-seeking. This purpose of this paper is not to do with making recommendations about appropriate parental help-seeking, nor with critically examining what many have described as an international trend in western welfare regimes towards increased intervention in parenting (Goldson and Jamieson, 2002; Garrett, 2007). Rather, the purpose is to draw attention to some taken-for-granted but fundamental aspects of the practical-moral organisation of parents' decisions-making with respect to the topic help-seeking. The applied context of this paper is England and Wales; however, the findings and discussion are of relevance to an international audience, given similarities between child welfare systems in England and Wales and those of North America, Canada and Australia.

1.2 A qualitative study was conducted between 2002 and 2005. In focus groups and interviews ${ }^{[1]}$, participants were prompted to consider the kinds of problems that welfare agencies/family support agencies typically deal with (parenting style and capacity, family stress to do with finance, relationships and children's behaviour, as well as lifestyle choices) and make decisions about appropriate help. The rationale for this focus was that whilst parental help-seeking with respect to certain areas of a child's life such as health might be considered normalised via the provision of universal services, in England and Wales services have always been provided selectively for 'welfare' problems. Thus, it might be expected that parental help-seeking in this context be subject to different moral or social considerations. Data was 
analysed using the tools of Membership Categorisation Analysis (MCA) devised by Harvey Sacks (1966, 1992) and further developed by Hester and Eglin (1997). MCA offers a method for the analysis of talk-ininteraction; it is a method of fine-grained qualitative analysis that focuses on participants' use of categories in talk. From detailed analysis of patterns in talk, the analyst is able to make observations about the shared commonsense or normative frameworks that social actors deploy in situated and contingent ways to make decisions, judgements and so forth.

1.3 The study found that when considering the welfare problems of parenting (frequently referred to by participants as, 'domestic', 'normal' or 'on the home front'), participants routinely made relevant the binary 'inside/outside' the family, indicating the central (normative) relevance of the membership categorisation device (MCD) ${ }^{[2]}$ 'family' in practical reasoning across the participant populations. The findings are discussed in relation to the present government's agenda that seeks to normalise help-seeking from formal services for problems of parenting (DfES, 2006, 2007). Whilst the observations made relate directly to parents' participation in research interviews, a suggestion is also made that welfare agencies made need to consider much more closely, those who present with 'no one to turn to'.

\section{Applied Context and background literature}

2.1 Recent developments in child welfare services in England and Wales place support for parenting as central to the welfare of children. Effective parenting has been central to the Labour government's programme of social investment and is key to the achievement of the five Every Child Matters outcome targets $^{[3]}$ for all children (DfES, 2003, 2004, 2006, 2007). Services now aim to engage families ${ }^{[4]}$ at an earlier point and to facilitate access to parenting support for a much wider population in the context of what the Treasury has termed 'progressive universalism' (DfES, 2003). The National Family and Parenting Institute, the helpline: Parentline Plus, children's centres and extended schools are all practical translations of this agenda. Recently Beverley Hughes (in her former role as Minister of State for Children) announced a $£ 30$ million investment in a further initiative, that of the parenting practitioners' academy (DfES, 2006). Early statements from the new (super) 'Ministry of State for Children, Schools and Families' led by Ed Balls and arising from the recent change of Labour Party leadership, indicate that there will be continued attempts to engage a broader range of parents in these support initiatives (Guardian, June 29. 2007).

2.2 Whilst parental help-seeking behaviour is, arguably, a critical ingredient in the process of engaging families earlier and prior to the onset of more serious problems, the extant literature offers only limited insights about parental help-seeking behaviour in the context of problems that child welfare agencies seek to address (Redmond et al. 2002; Broadhurst, 2003). Given that recent changes in both the organisation and ethos of support to parents amount to what Edwards and Gillies have termed a 'pedagogic consensus that expert knowledge and intervention should be the norm' (2004; p632), it is important to consider the extent to which this shift in ethos is compatible with the social organisation of parental help-seeking.

2.3 Knowledge about the social/moral organisation of parents' help-seeking decisions is limited, both nationally and internationally. The problem of those who are reluctant to seek help or 'hard to reach' is well documented (Oakley et al. 1998; Frost et al. 2000; Broadhurst and May-Chahal, 2005; Barnes, et al. 2006), yet we know little of how this reluctance is socially organised. The majority of studies of help-seeking in the context of parenting or family support have tended to focus on referral patterns and/or the uptake of formal services (Gibbons et al. 1990; Pavuluri and Luk, 1996; Keller and McDade, 1997; Kaniasty and Norris, 2000; Arcia et al. 2004; Peckover, 2003; Boddy et al. 2005; Ingram, 2007). However, in the face of problems of parenting, help-seekers have a number of options that do not necessarily culminate in formal service use. The focus on formal service use leaves unexplicated how individuals choose between the range of both informal and formal sources of support, which in the case of problems that can be considered 'domestic' or 'private' are relevant.

2.4 In the broader literature on help-seeking, early stage models offer a 'process' model of help-seeking, attempting to capture social actions prior to, as well as at the point of, service entry. According to these models, help-seeking approximates to three discrete stages: problem identification, deciding to seek help and actively seeking help (Darley and Latane, 1970; Keith-Lucas, 1972; Goldberg and Huxley, 1980). Whilst the stage models attempt to theorise process, social action is reduced to a set of rational-cognitive activities, again missing the social/moral element of help-seeking. Stage models emerged in a social scientific period in which positivist assumptions that dictated a split between normative and positive thought were very influential (Sayer, 2006); however, the conceptual emphasis of these models on instrumental reasoning has had a lasting influence (see, Ingram, 2007 for a very recent study). For example, there is a significant body of literature that has examined definitional issues, aiming to quantify differences between service users' definitions of need and those of service providers (Zahner et al. 1992; Pavuluri et al. 1995; Portwood, 1999; Arcia et al. 1998, Arcia, 2004; Meltzor et al. 2000). These studies suggest that if target populations are educated as to the 'proper' nature of problems, then appropriate (rational) help-seeking will follow. In 1992 Pescoscolido suggested that help-seeking be conceptualised as a social as well as rational activity; however, where any attempt to examine the 'social' has been undertaken, the moral-evaluative aspects continue to be erased. This omission is largely due to the influence of social psychology that offers, a priori, a number of 'objective' analytical frameworks for understanding human behaviour; once again conforming to the demands of a theory-practice divide (for example, Nadler, 2006; De Nooijer, 2003).

2.5 A notable exception to this trend, in terms of specific research aims, is a recent study by Gilles and Edwards (2004) that examined parents' 'views' and 'practices' regarding support and advice in the context of a study of 'resources in parenting'. The authors used "a 'baseline consensus' approach to look at parents' perceptions of change in parenting support, examining parents' norms with regard to help in parenting: practical, emotional, behaviour, health and education" (ibid: p627). The study was influenced by earlier 
studies by Finch and Mason of kin obligations (1991, 1993). The authors drew the important observation that whilst certain aspects of a child's development have been clearly delineated as the proper business of professional intervention for all children, notably education and health, this is not so for the domestic world of the child, that is, matters to do with parenting capacity (coping), quality of family relationships, lifestyle choices and so forth. The present study shares a similar aim to that of Edward and Gillies, but takes a markedly different methodological approach.

2.6 Edwards and Gillies (ibid) utilised a 'consensus baseline' approach. Using this approach the analyst counts individual responses and draws conclusions, given that adequate statistical significance is achieved, about 'consensus' (see Finch and Mason for a full discussion, 1991: 349-50). This method of analysing parents' 'views' or 'norms' is standard in social research; individual responses can be aggregated to draw conclusions about a larger population of respondents. The limitation of studies that focus on individual responses is that this method misses how 'norms' or 'views' are socially organised. In contrast, the analytic focus of the present study is not individual responses, but rather the sequential co-production of responses as elicited between and as a consequence of participant interaction (including the researcher). Wittgenstein suggested that everyday sense is both inter-subjective and conventional (1952). Thus, from the perspective of ordinary language philosophers, in understanding 'views' or 'attitudes', analysis needs to start with the description of intersubjectivity. This is quite a different starting point than that espoused by the cognate tradition of much of social research that reifies individual subjectivity (Coulter, 1982). Given the intents of this study: to examine the social organisation of parental decision making with respect to help-seeking, post-Wittgensteinian methods that examine the socio-logic of talk-ininteraction are well suited to this analysis of culture.

\section{Data collection}

3.1 A total of 24 focus groups and 48 interviews were conducted and audio-recorded. Participation in the interviews was on a voluntary/convenience basis, paying to ethical principles at outlined by the British Sociological Association (2002). Participants were recruited from two contrasting urban and rural communities in the North West of England. However, the communities were matched in terms of local provision of child-welfare services. Both localities were serviced by health-care facilities, schools, play group/child-care facilities, as well as statutory and voluntary sector family support provision. In the rural community, 12 focus groups were conducted with a majority white population, conducting 6 groups with male only participants and 6 groups with female only participants. The urban sample was drawn, 6 from a majority white population and 6 from a minority British-Asian population, again with half the groups

consisting of female participants and half the groups consisting of male participants ${ }^{5}$. Individuals were also recruited to the focus groups from a range of socio-economic backgrounds. Participants were also selected on the basis that they were parents or stepparents with at least one child under the age of 10 .

3.2 Participants were recruited to the focus groups by the researcher making contact with networks outside of formal services; for example, friends meeting in local pubs, women frequenting the same play group, individuals who worked together in local shops/factories. A decision to sample from networks outside of formal services was taken following the review of prior studies of help-seeking, which found that the majority of studies focused on service-user populations.

3.3 In the focus groups participants were presented with a vignette (amended for work with the minority ethnic population). The vignette comprised two parts posing welfare problems specifically to do with stepparenting, relationship conflicts, a child with emotional/behavioural problems and debt. An escalation of family problems was presented in part two of the vignette with an adult physically chastising a child. In the interviews, participants were prompted via a series of semi-structured questions to recount the decisions that they had taken with respect to parenting and specifically prompted to consider where they might seek help if they ever encountered more serious or taboo (violence/drug and alcohol issues) problems that impacted on the care of children. Interviews and focused groups were transcribed verbatim.

\section{Methodological approach}

4.1 This study is influenced by a particular variant of ethnomethodology that is concerned with the sociologic of practical reasoning and practical action (Jayyusi, 1984; Coulter, 1996). From this perspective all action is at once practical and moral. Participants' orientation to the topic help-seeking and their decisions are understood as subject to moral evaluation and approached via examination of the praxiological detail of practical reasoning. However, the study also takes from contemporary micro-ethnography an understanding that situated (moral) decisions are influenced by participants' knowledge of social processes (culture) that occur 'beyond the temporal and spatial horizon of the immediate occasion of interaction' (Erickson, 2004, $p$ viii). Thus, a place is found between the between the deterministic perspective of structuralism and the constraints of extreme situationalism.

4.2 As stated, ethnomethodogically informed studies focus on the organisation of practical action and practical reasoning; analysis of 'culture' is approached via detailed observation and description of the practical actions that make-up that world. Thus, the departure that ethnomethodology makes from other approaches to social research is that the study of the social world is approached from analysis of the situated co-production of social order.

\subsection{The concept of 'inter-subjectivity' is central to all variants of ethnomethodology. For} ethnomethodologists, social actors share in an expectation of corroborating perspectives and conceptual reciprocity (Pollner, 1974). It is this normative orientation of everyday practical action that provides the researcher with his/her standpoint for analysis. Garfinkel's breaching experiments (1963) provide clear examples of the normative organisation of practical action, he noted in his experiments that when intersubjective expectations were breached (for example a family member behaving as a stranger in their own 
4.4 Sacks developed a particular branch of ethnomethodological work, that of Membership Categorisation Analysis (see Search for Help, 1966 and subsequent lectures, 1992). He identified that categorisations and their devices formed part of the common-sense framework of members' methods and recognisable capacities of practical/moral sense-making (LC6, 1992). Following in the tradition of ethnomethodology, Sacks developed the 'toolbox' of MCA as a way of describing everyday practical reasoning and its normative orientation. In understanding culture or the moral order the researcher builds up a picture of the social world from fine-grained analysis of the categorical properties of talk (Hester and Eglin, 1997). While each occasion of categorisation places unique demands on social actors, the analyst can identify patterns in talk that enable conclusions to be drawn about inter-subjectively understood inferential resources. In this kind of analysis, the researcher's own normative orientation can also be a focus of analysis, with the researcher holding in common with co-participants, tacit categorical resources. This method avoids what Sayer has referred to as theory-practice contradictions:

'social scientists are prone to theory-practice contradictions, that is, to produce accounts of action which do not fit their own mundane behaviour, and which they themselves could not live by' (2004, p3)

4.5 Sacks objection to what he termed 'conventional' methods of social science was on the basis that social scientists failed to grapple with the fine detail of interaction and thus, the social organisation of practical reasoning and communication. He noted that whilst it is commonplace for social research to be interested in categories, the categories that usually draw the attention of the researcher are those that he/she assumes as relevant a priori, for example 'gender' or 'social class', or imposes deductively on data sets. MCA requires that the analyst moves away from the familiar categories that organise this or that body of literature and instead commence with the principle that 'no category of sociological description' should be used in such a manner as to neglect 'the commonsense ways' in which social actors themselves use it for practical purposes (LC6, p41-42, 1992).

4.6 Sacks coined the notion of programmatic relevance; this analytic concept is central to the present study and is particularly useful in getting to social actors' commonsense or normative assumptions as displayed in category use. To simplify, it is frequently evident in talk that social actors share certain normative assumptions; these assumptions are there 'in the background' and can be orientated to (mutually) by social actors. For example, in conversations about school, the categories teachers and pupils are programmatically relevant. In conversations about weddings, the categories 'bride' and 'groom' are programmatically relevant. Sacks coined this term from his analysis of telephone calls made to a helpline for suicide. He noted that if a caller expressed suicidal intentions, the help-line operator could assume the relevance of family members for help and ask the caller about whether any family members could offer help (prior to any disclosure by the caller as to the nature of his/her family network). On account of the programmatic relevance of family, the caller could simply ask: 'Can you turn to anyone in your family?' and such questions would be understood as mutually and contextually relevant. Sacks also noted that if a category is programmatically relevant, then non-incumbency (the absence of the category) would elicit enquiries. For example, at a wedding, the absence of the bride would elicit questions as to her whereabouts. The following extract from Sacks is useful:
'The notice of non-incumbency is not a straightforward matter. For example, A may say of B, "you don't have a wife? Might be something to which B could properly respond, "No but I don't have a houseboy or a lover, or a lot of money- How is it that the question "you don't have a wife as against, you don't have a chauffer, becomes properly noticed, spoken of, worried about, proposed as some trouble and the rest?' (Sacks, 1966, p43)

4.7 Whilst Sacks's work Search for Help (1966) provides a practical illustration of the application and value of MCA, his particular methods of explicating the social organisation of obligations to provide or seek help, have failed to gain the interest of researchers working in applied fields of health and social welfare. Fine grained methods of data analysis such as MCA often result in questions of 'so what' by colleagues in social research as the methods of MCA are not seen as dealing with the real issues of social structure and social order. The findings that the MCA technologist produces may seem so mundane as to be uninteresting. However, as proponents of MCA have been at pains to point out, the departure MCA makes from other approaches to social research lies not in disputing the relevance of social order, but rather the starting point for investigation. Jayyusi describes MCA's project as to do with 'uncovering the various cultural conventions that enable the production of sense and that inform the organisation of social relations' and hence social order (1986, p2). For a fuller discussion of the position of ethnomethodological studies and social order see Coulter's paper: Human practices and the observability of the 'Macro-Social' (2001).

4.8 The methodological approach taken in this work does not suggest any superior or transcendental vantage point; rather, as Barnes and Law have considered, the practice of ethnomethodology (like any other form of social research practice) is "beyond justification in any other than a circular way which involves its own practice as a criterion of judgement' (Barnes and Law, 1976, p236). In this study, the analytic approach reflects the aim of the study: to elicit understandings about the shared or inter-subjective understandings that inform parents' decision-making. Thus, analysis has focused on the commonalities of practical-moral reasoning across the focus group and interview populations. Alternative methodological approaches are of course equally valid for other purposes, such as the use of methods that examine differences between the sample groups or the impact of participants' social locations.

\section{Working with the transcripts using MCA}

5.1 Starting work with the transcripts, MCA prompts the researcher to ask, 'what are participants (including 
the researcher) doing with categories? Participant activities of collecting together categories, drawing boundaries between and putting categories in order are the focus. Given the centrality of the concept of inter-subjectivity, co-produced sentences, as manifest in contiguous (latched on or joined together) utterances are particularly illuminative. The sequential organisation of talk is not an obstacle, but rather a resource in this kind of analysis (Hester and Eglin, 1997). Instances of condensed speech are also noteworthy as they provide an opportunity to examine how participants provide 'correct' readings of this kind of utterance. Condensed speech requires that participants (speakers and hearers) make use of normative and inter-subjective understandings for correct interpretation.

5.2 The researcher also identifies utterances that are made 'straight off' (Sacks, 1992) i.e. treated as mundane by co-conversationists, or, in contrast, utterances that prompt requests to elaborate or clarify. The data was also examined to see whether any membership categorisation device (MCD) presented as programmatically relevant.

5.3 A number of patterns were initially identified and noted across extracts in talk. Initial observations were further verified from repeat analysis of the draft transcripts. Clearly participants' practical reasoning presented as a complex nesting of inferential work; however, the focus of this paper will be on the centrality of the MCD 'family' in participants talk about 'help-seeking' as consistently displayed across the different participant population groups. Interview participants have been labelled $\mathbf{P}$, and focus group participants A - D. The researcher is $\mathbf{R}$. Line numbering has been applied to longer extracts and the following notation has been applied:

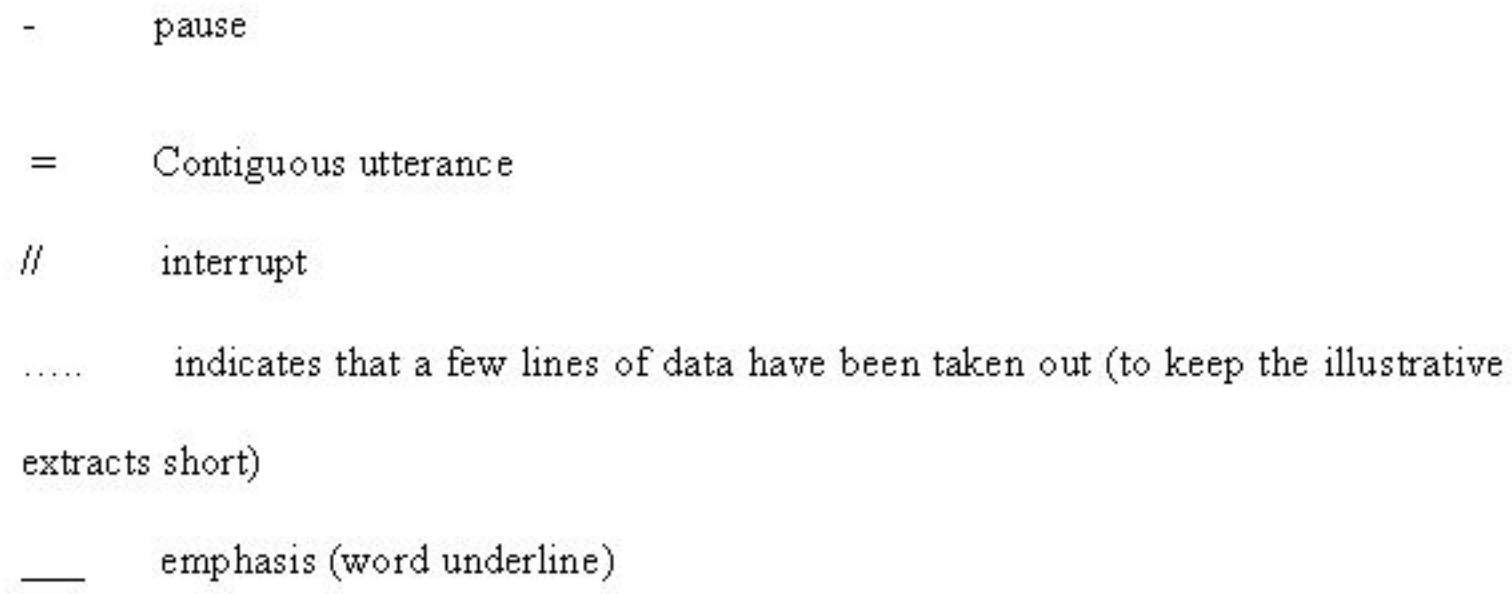

The interview extracts are also labelled thus:

\author{
FGMW focus group, majority white population \\ FGBA focus group, British-Asian population \\ INTMW interview, majority white population \\ INTBA interview, British Asian population
}

Findings

(i) Seeking help 'inside' and 'outside' the family: the centrality of the MCD 'family' 


\section{Extract 1}

1 A : Alright, Mike wants some respect - but he shouldn't be putting his hands on kids that aren't his $\cdots \cdot$

$2 \quad \mathbf{R}$ : do you think there are any problems the family need help with?

3 B : erm, I think Rachael needs some help, erm - something is causing her a lot of anxiety

4 C: erm, it sounds as though possibly, it might be a bit hectic when there's 3 of them (children), all

5 different ages and different personalities, perhaps they've nushed it a bit.

$6 \mathbf{R}$ : OK, imagine Jenny wants to ask for some help or advice, where is she going to go first of all-

7 family or somewhere professional or her mother or?

8 B: she'll go to her mother first of all

9 C: yeah, family, her mother first=

$10 \mathbf{R}:=$ her mother first of all

(FGMW)

6.1 Participants routinely made reference to the MCD family ${ }^{[6]}$ when presented with either the vignette or asked questions about their own help-seeking behaviour. Extract 1 above is taken from a focus group, the participants have identified a problem with the new dad who 'shouldn't be putting his hands on kids that aren't his' (line 1) and that Rachael (the child in the vignette) needs some help: 'something is causing her a lot of anxiety' (line 3). The participants then suggest that Jenny (the mother) can go to 'her mother' for help (line 8). C, who says 'yeah, family, her mother first', confirms this response. Participants (including the researcher) share in the sense that the MCD family and the sub-category mother are candidates for help in this instance. Sequentially, the utterances in which the category 'mother' and 'family' are suggested are made straight off; they require no elaboration and elicit no requests for clarification. The participants are also able to offer the MCD 'family' and the sub-category 'mother' as candidates for help, although the vignette did not present the detail of the relationships between Jenny and her family. It is the normative orientation of participants to the MCD family as the first port of call that enables them to fill in this context. In extract 2 below (lines 16-18) the same normative orientation is observable, with participants filling in: 'she's got her mother and sisters to talk to' in the context of this 'normal situation':

\section{Extract 2}

1. B: you don't like to see someone else disciplining your child

2. A: pushing your child around

3. B: no it's yours, you know someone else coming in/

4. A: it's not so bad if it's you're own but somebody else coming in//

5. B : if it was the child's father, but somebody else coming in and trying to be the man of the

6. house - must be very difficult

7. R: Do you think there are any problems that the family need help with?

8 A: Not that//

9 C: Outside the home? - No probably not=

10 A: =no it's just like a normal family situation now - you know/l

11 B : No, it's just a normal family, sounds like a normal family now=

12 C: $=$ like a normal family now/l

13 A. Dunnit now? - You know=

14 B: =normal situation//

15 C: Normal situation, yeah

16 B: And she's got her mother and sisters to talk to, if she feels that she needs to

17 thrash it out with somebody. It's not as if she needs counselling or anything

18 because they do that don't they - the extended family do that you know.

\section{(FGMW)}

6.2 In extract 2, the participants have again identified that the new dad is causing problems for Jenny and her children. They also concluded that whilst 'someone else coming in' and 'pushing your child around' is a problem, this is a 'normal situation'. When asked where Jenny will seek help, participants offer family members. Without knowledge of the individual family relationships, participant $\mathbf{B}$ is able to suggest that the fictitious character Jenny can 'thrash it out' with her mother and sisters, further qualifying her category choice with the factive ${ }^{[7]}$ and rhetorical statement that invites agreement: 'they do that don't they- the extended family do that you know' (lines 16-18). 'You know' is a rhetorical device that trades on an assumption of the normative orientation of co-conversationists to the device family for its sense. 
6.3 On account of the central relevance of the MCD family for help in this context, participants frequently made reference to the binary inside/outside the family (outside makes relevant inside). That participants collected together categories around the category family in this way, again indicates that for help in this context the MCD family is centrally referential. Family is the referent that allows practical reasoning to tip in one direction or another. In extract 2 above (line 4), C asks 'outside the family?' and then in her next utterance dismisses outside help. The remainder of this conversation is axiomatic around the boundary inside/outside the family, with mother and sisters suggested as a source of help and outside help (counsellors or anything) dismissed. The next short interview extract, finds the researcher using this same inferential resource:

\title{
Extract 3
}

R: Imagine there's a problem that you can't go to your family with and you need to go to an outside agency, what would you be looking for in that outside agency?

P: probably - err - discretion being vital

(INTBA)

6.4 In this extract taken from an interview, practical reasoning is again axiomatic around the MCD family. The researcher rules out the family (you can't go to your family) and given her understanding of the boundary between inside and outside help, she can thus push the participant to consider 'outside' help.

6.5 Extract 4 below is also taken from an interview with a male participant from the minority British-Asian population and provides a further example of both the researcher and the participant's normative orientation to the MCD family and its sub-categories as relevant for help in the context of a 'domestic' problem. At line 5 , the participant states 'we sort it out'. 'We' is an example of condensed speech; yet, the researcher is able to make a correct guess, 'is that you and your wife?' It is possible to consider that if the researcher had said: 'and is that you and your social worker? that the question would have been treated as curious. In extract 3, without detailed knowledge of the participant's family, the researcher makes a correct guess, simply on the basis of what everyone knows about the social organisation of help.

\section{Extract 4}

$\mathbf{R}$ : What about on the home front then? If a problem crops up at home - err - it could be a domestic problem?

P: A domestic problem or - ?

R: It could be a domestic problem or child with a health problem or financial problem

P: Well, domestic problem, we sit down talk about it, compromise in whatever way, sort it out -

R: And is that you and your wife or -?

P: Oh yeah, if we have any arguments we usually sit down and talk about it, find out what the problem is and compromise.

(INTBA)

\section{(ii) Putting categories in sequence}

6.6 For participants it was relevant to consider those callable for help in a sequence, with those considered 'inside the family circle' as a first port of call:

\author{
Extract: 5 \\ $\mathbf{R}$ : Can I just move you down to the second question - if Jenny's going to get \\ help, who do you think she would turn to for help? \\ C: In the first instance? \\ $\mathbf{R}:$ In the first instance \\ C: Her mother= \\ A: $=$ mother or sisters
}

(FGMW)

6.7 In extract 5, again the researcher asks participants in a focus group where Jenny might seek help and her question is met with a further question from C: 'in the first instance?' Without knowledge of the point in this sequence to which the researcher refers, the participant is unable to answer the question, thus, she 
seeks clarification. When $\mathbf{R}$ confirms for $\mathbf{C}$, 'in the first instance', both $\mathbf{C}$ and $\mathbf{A}$ are then able to offer the categories 'mother' and 'sisters'- they co-produce a response with A confirming in this contiguous response, C's prior selection of the category 'mother'; $\mathbf{C}$ also adds 'sisters'. The response from C: 'in the first instance?' takes the analyst into the resources, which $\mathbf{C}$ is drawing on in order to choose between a range of help-providers. For participants, it is socially sanctioned and agreed to consider an order to helpseeking, with the MCD family, normatively a first port of call.

6.8 Extract 6 below provides a further illustration of sequencing work:

\section{Extract 6}

R: Ok, so that's sort of general, that's fine. Erm - can you tell the who you would turn to for help with bringing up your children?

P: First and foremost my husband, then after that family (R: Ah ha) - particularly my mum or his mum.

R: so family would be your first port of call.

\section{(INTMW)}

6.9 In response to the researcher's question about 'bringing up children', $\mathbf{P}$ answers: 'first and foremost. then...my mum or his mum'. R responds with the confirmation 'family would be your first port of call', illustrating that she shares in the sense of P's sequencing work. For both researcher and participant sequencing is a known-in-common interactional resource. From the transcripts, it is possible to see category selection, expressed in the form of a set of contingencies; some sources of help only become relevant, after other sources have been considered (first).

\section{ii) Programmatic relevance}

6.10 In further explicating participants' normative orientation towards the MCD family as the first port of call, Sacks' notion of programmatic relevance (as discussed above) provides a useful analytic concept. In extract 7 below, the interviewer has again set the context for the participant by asking where the participant might seek help if a problem came up at home of a domestic or personal nature. The participant describes seeking help as 'difficult' and then moves on to explain that difficulty:

\section{Extract 7}

R: So, you'd try and sort things yourself first?

P: Yeah, we'd try and sort it out ourselves first. Erm - err - I think K would approach her parents and farnily first, before I would approach anybody - erm - because - I've only got like - there's only like my mother- who I'm not like massively close to that I can talk to about things like that. I - err I always feel sort of - err - uncomfortable with things like that. But I think $\mathrm{K}$ would actually go to her family first, either her mum and dad or her aunty in town. I'm not sure who I'd go to be honest very difficult. - $\underline{\mathrm{K}}$ 's family first (R: Yeah, yeah). She's comfortable speaking to them about things like that, whereas I'm not comfortable speaking to my parents about things like that, so I leave it to her

\section{(INTMW)}

6.11 In this extract, participant $\mathbf{P}$ offers a spontaneous explanation of why he would not ask his own mother for help. Whilst the researcher has not requested this information directly, the explanation is treated by both speaker and hearer as inter-subjectively relevant. His mother's non-incumbency of the category 'primary candidate for help' requires explanation; this turns on inter-subjectively understood expectations about mothers and their obligations to provide help. $\mathbf{P}$ explains that he has a mother but he would not choose to seek help from her stating 'who I'm not like massively close to'. That $\mathbf{P}$ feels he needs to account for the non-availability of family members indicates the programmatic relevance of the categories that constitute the device family. When a participant could not invoke help from a family member, then this was something that required explanation.

6.12 In extract 8 below, in the final question A states: 'there's no mention of grandmas or granddads'? Searches such as this, again turn on the programmatic relevance of the categories that comprise the device family for help in this context. 


\title{
Extract 8
}

B: Who do you think Jenny would tum to help for?

D: Her mum//

B Jenny is the mother//

D: NO, Jenny would speak to her mother

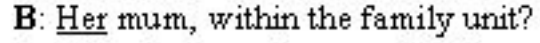

D: Yeah, because her mum has been quite helpful,

A: There's no mention of grandmas, granddads?

(FGMW)

6.13 In this extract, the programmatic relevance of those 'within the family unit' for help in the first instance renders absence of close family members or those inside the family an accountable matter. This is not to imply that all social actors will state that a family member is the first port of call. Rather, it is to state that in talk there are sufficient accounts and curious accounts, and if a social actor fails to mention family members as a source of support, co-conversationists can routinely enquire as to their whereabouts.

\section{iv) 'Somebody', 'anybody' and 'nobody'}

\author{
Extract 9 \\ R: What about Mike? Is he going to go anywhere for help? \\ A: I think Mike would probably go for the same type of person, somebody that he can trust. - It \\ might be his best mate. It might be his father. It might be his mother. \\ R: It might be his mother? \\ A: Err - somebody again who he knows it isn't going to go any further with// \\ B: It doesn't say whether Mike's close to family or not, does it? Because if he's not close to family \\ then he wouldn't have any body to go to.
}

(FGMW)

6.14 Across the transcripts, because of the centrality of those 'within the family' for help, non-availability of family members enabled participants to conclude that an individual would have 'nobody' to turn to. In extract 9 the participants conclude that if Mike (male character in the vignette) is not 'close to family' then he 'wouldn't have anybody to go to'. Given the large number of 'outsiders' that would be relevant sources of help for Mike (GP, counsellor, social worker, various help-lines), this poses the question of how it is that participants can suggest that the absence of close family, means Mike 'wouldn't have anybody to go to?' On account of the programmatic relevance of family, absence of a family member doesn't mean that outsiders suddenly become 'somebody'. This is a very fundamental observation, but clearly has implications for those who provide help from 'outside'. The following extract provides a further example:

\section{Extract 10}

R: Is Sabiha going to go and ask for help?

B: Well, she could go to her family and see what help they can give her=

C: $:$ Or friends

D: Or a counsellor, if she doesn't want to talk to anybody, if she doesn't want her family to know, then she can talk to a counsellor

B: But in reality, will she go there?

D : If the family don't support her, where is she going to go? If she's got nobody to help her?

B: I know a lot of people that don't go anywhere.

\section{(FGBA)}

6.15 Use of 'anybody' and 'nobody' is interesting in this extract. D says 'if she doesn't want to talk to anybody ...she can talk to a counsellor'. How is it that a counsellor is not included in D's category collectivity 'anybody' and is by implication nobody? Again, talk is axiomatic around the device 'family', those within the family are 'somebody', and because participants group together candidates for help in this way, it enables D to (accountably) draw a categorical boundary between 'anybody' and the 'counsellor'. Later in the extract $\mathbf{D}$ provides a further illustration of this category collectivity work ${ }^{[8]}$, when she says: 'If the family don't support her... if she's got nobody to help her... where is she going to go if she's got nobody to help her? (lines 7-8). The use of 'somebody' 'nobody' and 'anybody' is based on and constitutes a boundary between inside and outside 'the family'. 


\section{Discussion and conclusions}

7.1 This study has sought to draw attention to some fundamental but taken-for-granted aspects of the practical-moral organisation of parents' decision-making with respect to help-seeking. Focusing on the fine interactional detail of situated talk, analysis has identified that for problems on the 'home front', ranging from 'pushing your child around' to a 'domestic' issue, those 'within the family unit' were strongly morally implicated as first choice categories for help (extracts 1 and 2), such that if a participant considered an individual to have no one 'inside' the family to turn to, then a conclusion could be drawn that they had 'nobody' (extracts 9 and 10). The MCD 'family' presented as a centrally relevant, inter-subjective resource for participants when presented with questions about help-seeking.

7.2 Focusing on the socio-logic of practical reasoning, the centrality of the MCD 'family' was evident in participants 'sequencing work'. Participants placed categories in order, with family members first. This sequencing work was routinely treated as a 'natural order', mutually understood and normative, such that when a selection of a family member was made, no questions, queries, or calls to elaborate were required (extracts 5 and 6). In contrast, 'outside' help for the welfare problems of family was very much a residual option (if an option at all, extracts, 3,9 and 10). In addition, analysis found that there was an exclusivity to the categories that constitute 'family', which provided for the participants' maxim in situated decisionmaking: if categories inside the family are available, use them first (extracts 7 and 8). For example, in extract 2, participant B states: 'she's got her mother and sisters to talk to, if she feels she needs to thrash it out...It's not as if she needs counselling or anything, because they do that don't they - the extended family...'. As this extract clearly illustrates, the assumed availability of the extended family, enables the participant to conclude that 'counselling or anything' was not required. The centrality of the MCD family as an inter-subjective categorical resource in participants' decision-making also enabled participants to make correct interpretations of condensed speech (extract 4) and required that participants explain the absence of family members as sources of help (extract 5). MCA approaches the study of 'social order' or 'culture' via analysis of the taken-for-granted inferential resources of categorisation; the findings from such studies often appear mundane because they simply draw attention to what everyone already knows. Yet the centrality of the category 'family' in participants' decision-making is relevant for policy makers and practitioners and prompts a number of lines of discussion.

7.3 In Beverley Hughes's forward to the document 'Parenting Support' (DfES, 2006) she commenced with the statement that 'parenting is first and foremost a private and personal affair' (p1). Yet, in the same forward, she also outlined a strategy based on increased formal support initiatives that aim to 'normalise' professional help with the parenting task. What Hughes misses, as suggested by this study, is that if parenting is first and foremost a private affair (extracts 1 and 2), then seeking formal help is somewhat at odds with the behaviour of the competent parent who should sort out his or her problems 'in-house'. Whilst early intervention and prevention are the cornerstones of refocused children's services, there has been a failure to address this fundamental moral tension within welfare provision that at once valorises selfsupporting families, yet at the same time aims to encourage more parents to seek formal help at an earlier point. The new Ministry for Children, Schools and Families, led by Ed Balls, is in its infancy, but given that early indications are that services will continue to be organised according to progressive universalism (Guardian, 29 June, 2007), this may lead result in parents seeking help at a later, rather than earlier point, having exhausted their own resources first. This study lends empirical support to this observation, with participants clearly drawing a boundary between help 'inside' the family - a first port of call, and help 'outside' the family a residual option when all else fails.

7.4 Family life in England and Wales has a long history of being based on self-supporting families with support services only aiming to compensate, where there is risk that the family cannot achieve this goal. The 'social' has always aimed to improve the lives of children where parents are deemed in some way inadequate and individually accountable for their failings (Stephens, 1945; Rose, 1990; Clarke, 2006; Garrett, 2007). During the 1980s and early 1990s the influence of Conservative family policy, with its strongly individualistic ethos, raised the moral profile of the traditional self-supporting family and drew more closely into focus the failing 'underclass' who were in need of corrective intervention (Fox Harding, 1999). Whilst the Labour government has sought to broaden support for parenting in the context of the social investment state, key features of Labour's modernising agenda have been conditional benefits and restricted eligibility to services (Jordan, 2000; Garrett, 2007). A number of commentators have noted that, peel away the rhetoric of inclusion, and underneath one finds a specific concern with 'socially excluded families' who are deemed to be failing or at risk of failing (Gillies, 2005; Clarke, 2006). Thus, the problems of social isolation, low self-esteem or family stress, have never achieved the legitimacy of, for example, medical problems, simply because not everybody is encouraged to seek help in this context. As Sacks noted, achieving legitimacy is organised through doing that which everybody ordinarily does (Sacks, 1992).

7.5 Labour's latest policy developments are based on an agenda of 'Every Child Matters' (DfES, 2003) in the context of progressive universalism (DfES, 2003), but the development of new initiatives such as children's centres has, once again, commenced in designated areas of highest need (DfES, 2003). The latest launch of further parenting initiatives (Every Parent Matters, DfES, 2007) falls short of a systematic attempt to 'institutionalise' support for all parents and there remains a clear emphasis on parents whose children are at risk of failing; for example, children at risk of offending behaviour. In the document 'Parenting Support' (DfES, 2006) there is substantial reference to the government's 'Respect ${ }^{[9]}$ agenda and the need to support parents whose children commit crimes. In this context, the findings from this study, that parents clearly consider 'outside' help a residual resource, is not surprising.

7.6 There is a wealth of evaluative research evidence that has found that there are problems with the uptake of parenting and family support initiatives (Oakley, 1998; Frost et al. 2000; Broadhurst and MayChahal, 2005; Moran and Ghate, 2005) and this is not just in England and Wales, but has been found 
internationally in countries that have a similar pattern of welfare provision to families (for example, Leventhal, 2001 in the USA). If parental help-seeking is firmly embedded in a social-moral order that, as stated, valorises self-supporting families, then it may be difficult to offer help from 'outside'. The present government's strategy of support to families includes an element of direct financial support in the form of tax credits; this study suggests that further direct provision of practical, financial and housing support to families would fit with the social organisation of parents' own help-seeking preferences. Enhancing 'insider' resources would increase a family's capacity to share in mutual relationships of support with family and friends.

7.7 That participants in this study, co-constituted a very clear moral boundary in talk between 'inside' and 'outside' help, has some very fundamental implications not just for policy makers, but also practitioners involved in the frontline delivery of policy initiatives. First, for those who offer help from 'outside' (for example, parenting practitioners), with 'domestic' or 'personal' problems of families, this study suggests that availability of 'insider' resources will present as a key obstacle. Outside agencies compete with those in-house who are not only legitimate sources of help, but should be called on first (see Sharrock, 1990 On owning knowledge). From this study, it is possible to speculate that problems of non-engagement may be as a result of the help-seeker perceiving the help as superfluous to requirements, if resources are perceived as effectively and normatively offered in-house (extract 2). As stated in the introduction, families have tended to enter child welfare services following professional or third party referral. From this study, there is significant potential for unsolicited third-party referral to breach the socially sanctioned methodological concerns of the help-seeker to do with 'family first' and 'no one to turn to'. In the present study, the centrality of sequencing work that places 'family first' suggests that it is difficult to make requests to outside agencies on behalf of another for the 'domestic' problems of family, unless this form of advocating has been requested and the individual themselves deems that they have no resources 'within the family unit'. This is not to suggest that a skilled worker might attain an 'insider' position, but to suggest that the difficulties agencies experience around engagement may be as a consequence of the availability of members of the individual's social network who are properly considered the first port of call.

7.8 The practice of professional diagnosis of need can be traced to the work of Mary Richmond (1917), but, is still very much a feature of contemporary children's services (not just in England and Wales, but in many other western welfare systems). Developments in children's services towards integrated provision continue to place the responsibility to identify a child in need, very firmly in the hands of a range of professionals and according to a range of professionally defined problems (DfES, 2003, DfES 2004, DfES, 2006, DfES, 2007). Professionals are trained to identify organisationally relevant problems that range from perceived failings in parenting style, for example neglect, through to children's behaviour, domestic violence or sexual assault and refer families for help on that basis. This organisation of referral making raises a second issue, given the findings from this study.

7.9 For participants in this study, it was not the problem of 'a smack' or any other presenting event or incident that prompted consideration of 'outside' help, but rather, that there was 'no one to turn to'.

According to the participants in this study, a parent is more likely to seek help from outside on the basis of 'no one to turn to' than issues to do with parenting style or children's behaviour. This is quite a different sort of 'problem' and one that may be difficult to explain to outside agencies whose lens on the social world is more attuned to the presenting problems of an incident of, or risk factor for, child maltreatment (Broadhurst et al. 2007). For outside agencies and despite the well documented changes in family form, kin networks and patterns of social mobility (Burrows, 1999; Silva and Smart, 1999; Featherstone, 2004), the problem of 'no one to turn to' is not in itself likely to trigger a welfare response. As a number of studies have indicated practitioners tend to overlook social network issues, despite the influence of an ecological perspective on recent assessment practices (Jack and Jill, 2003; Sanders and Roach, 2007; Sheppard, 2007). Whilst it would be naïve to think that services could simply shift away from the dominant model of professional diagnosis of need, attention does need to be drawn to how practitioners can identify and respond to the issue of 'no one to turn to'. Demographic changes, as discussed by such as Featherstone (2004), may in fact mean there are a larger numbers of parents who find themselves in this position.

7.10 To conclude, the findings from this study suggest that current policy initiatives that seek to 'normalise' formal support for a broader range of parents, present as somewhat at odds with parents' own moral understandings about appropriate help-seeking. Policy statements such as the following: 'it is the good parent that seeks help when they need it not the poor one' (Every Parent Matters, p42, 2007) are not well grounded in an evidence base concerned with how parental help-seeking behaviour is socially organised. This study concurs with the findings from Edward and Gillies (2004), that policy-makers have a long way to go if they wish to achieve a significant change in cultural norms and practices regarding help-seeking and the parenting task.

\section{Notes}

${ }^{1}$ This study is informed by ethnomethodology but does not share with ethnomethodology a belief in the superiority of 'naturally occurring' data. The paper illustrates how MCA can be fruitfully brought to bear on what ethnomethodologists have termed 'contrived' data. The position of the study if further outlined in the methodology section.

2 Sacks distinguished between membership categorisation device(s) (MCD) and categories. A membership categorisation device is a 'bigger' category that draws together and subsumes sub-categories. In this study the MCD family is the device, which when used in talk, makes relevant the sub-categories, mother, sister, grandmother, brother and so forth. 
${ }^{3}$ In 2003, the government published the 'Every Child Matters' Green Paper. This Green Paper proposed very significant reforms to the landscape of children's services in England and Wales. The proposals sought to broaden services to all children and are organised around five key outcome targets for children, which are: Being Healthy, Staying Safe, Enjoying and achieving, Making a positive contribution and Economic Well-being.

${ }^{4}$ The term 'family' is used throughout this paper; however, the majority of those using/referred to family support services are single female-headed households with children living in conditions of socio-economic deprivation. This study does not challenge participants' normative orientation to 'family'; however, this is not with the intention of promoting a universal model of family.

${ }^{5}$ Given the focus of MCA is on the categories that participants make relevant, the participants' own social locations have not been analysed in detail in this paper. The study did not find that participants rendered their own social locations (gender/social class/ethnicity) centrally relevant in decision-making.

${ }^{6}$ Who is 'within the family unit' is an individual matter - categories are indexical. Participants routinely made reference to female kin; however, close friends were also mentioned. In the context of changing patterns of family, it may be that many individuals would include close friends as 'insiders' or a first port of call. The issue here is that the centrality of the device 'family' renders clear a boundary between inside and outside help.

7 'Factive' means expressed as a fact.

8 'Work' in this sense means, the work of categorisation or practical reasoning. Participants use category collectivities to enable them to make decisions /organise choices about help-seeking.

${ }^{9}$ The Respect agenda, as laid out in the Respect Action Plan, is a recent Labour government initiative that aims to combat anti-social behaviour and prevent children and young people developing further offending behaviour. Part of the Respect Action Plan is to target families 'at risk' with intensive family support programmes (introduced in 2006) and to use enforcement strategies to ensure targeted families engage with support offered.

\section{References}

ARCIA, E. and FERNANDEZ, M.C. (1998) 'Cuban Mothers' Schemas of ADHD: Development, Characteristics and Help Seeking Behaviour.' Journal of Child and Family Studies, vol. 7, pp.333-352.

ARCIA, E., FERNANDEZ, M. C. and JAQUEZ, M. (2004) 'Modes of entry into services for young children with disruptive behaviours', Qualitative Health Research, vol. 14, pp.1211-1226.

BARNES, J., MACPHERSON, K. and SENIOR, R. (2006) Factors influencing the acceptance of volunteer home-visiting support offered to families with babies, Child and Family Social Work, vol. 11(2) pp107-117

BARNES, B. and LAW, J. (1976) 'Whatever should be done with Indexical Expressions?' Theory and Society, vol. 3, pp.223-237.

BRITISH SOCIOLOGICAL ASSOCIATION (2002) Statement of ethical practice for the British Sociological Association. <http://www.britsoc.co.uk/equality/Statement+Ethical+Practice.htm> (accessed, March, 2007)

BODDY, J., SMITH, M. and SIMON, A. (2005) Telephone Support for Parenting: An evaluation of Parentline Plus', Children and Society, vol. 19, 278-291

BROADHURST, K. (2003) 'Engaging parents and carers with family support services. What can be learned from the literature on help-seeking?' Child and Family Social Work, vol. 8, (4), pp.341-350.

BROADHURST, K. and MAY-CHAHAL, C. (2005) 'Children missing from school systems: Exploring divergent patterns of disengagement in the narrative accounts of parents, carers, children and young people', British Journal of Sociology of Education, vol. 26 (1), pp.105-119.

BROADHURST, K., MASON, C. \& GROVER, C. (2007) Sure Start and the 're-authorisation' of child protection practices. Critical Social Policy (in press).

BURROWS, R. (1999) Residential mobility and residualisation in social housing in England. Journal of Social Policy, vol. 28, pp27-52.

CLARKE, K. (2006) Childhood, parenting and early intervention: A critical examination of the Sure Start national programme. Critical Social Policy, vol. 26 (4), pp 699-721.

COULTER, J. (1982) 'Remarks on the conceptualisation of social structure', Philosophy of the Social Sciences, vol. 12 (1), pp.33-46.

COULTER, J. (2001) "Human Practices and the observability of the 'Macro-social'." Reprinted as revised in T Schatzki (ed.) The Practice turn in contemporary theory, Routledge, London. 
DARLEY, J. and LATANE, B. (1970) The unresponsive bystander: Why doesn't he help? Appleton-CenturyCrofts.

DE NOOIJER, J., LECHNER, L. and DE VRIES, H. (2003) 'Social psychological correlates of paying attention to cancer symptoms and seeking medical help', Social Science and Medicine, vol. 56 (5), p 915

DFES (2003) Every Child Matters, London, Stationery Office.

DFES (2004) Every Child Matters, Change for Children. London, Stationery Office.

DFES (2006) Parenting Support: Guidance for Local Authorities in England. London, Stationery Office.

DFES (2007) Every Parent Matters. London, Stationery Office.

EDWARDS, R. and GILLIES, V. (2004) 'Support in parenting: Values and Consensus regarding who to turn to'. Journal of Social Policy, vol. 33, pp 627-647

ERICKSON, F. (2004) Talk and Social Theory: Ecologies of speaking and listening in everyday life. Polity, Cambridge.

FEATHERSTONE, B. (2004) Family Life and Family Support: A feminist Analysis. London, Palgrave/Macmillan.

FINCH, J. and MASON, J. (1991) 'Obligations of kinship in contemporary Britain: is there normative agreement?' British Journal of Sociology, vol. 42(3), pp345-367

FINCH, J. and MASON, J. (1993) Negotiating Family Responsibilities, London, Routledge.

FOX HARDING, L. (1999) "Family Values" and Conservative Policy, in G. Jagger and C. Wright (eds) Changing Family Values, p 119-135. London, Routledge.

FROST, N., JOHNSON, L. STEIN, M. and WALLIS, L. (2000) 'Home-Start and the Delivery of Family Support', Children and Society, vol. 14, pp.328-342.

GARRETT, P. M. (2007) " 'Sinbin' solutions: the 'pioneer' projects for 'problem families' and the forgetfulness of social policy research." Critical Social Policy, vol. 27 (2), pp203-230 (doi: 10.1177/026108306075711)

GARFINKEL, H. (1963) A conception of and experiments with 'trust' as a condition of stable concerted actions. In O. J. Harvey (ed.), Motivation and Social Interaction. New York : Ronald Press.

GIBBONS, J. (1990) Family Support and Prevention: Studies in Local Areas, London: HMSO.

GILLIES, V. (2005) 'Meeting parents needs? Discourses of "support" and "inclusion" in family policy,' Critical Social Policy, vol. 25(1),pp 70-90

GOLDBERG, D. and HUXLEY. P. (1980) Mental illness in the community: The pathway to psychiatric care, London: Tavistock Publications.

GOLDSON, B. AND JAMIESON, J. (2002) 'Youth Crime, the 'Parenting Deficit' and State Intervention: A Contextual Critique', Youth Justice, vol.2 (2) pp82-

GUARDIAN (Newspaper), (2007) Balls take control of new ministry for children, June, 29. $<$ http://society.guardian.co.uk/children/story/0,,2114537,00.html>

HESTER, S. \& EGLIN, P. (1997) Culture in Action: Studies in Membership Categorisation Analysis. International Institute for Ethnomethodology and Conversation Analysis. University Press of America, Washington D.C.

INGRAM, E. B. (2007) 'A comparison of help-seeking between Latino and Non-Latino victims of intimate partner violence, ' Violence Against Women, vol. 13 (2), pp159-171

JACK, G \& GILL, O. (2003) The Missing Side of the Triangle: Assessing the importance of family and environmental factors in the lives of children. Barkingside: Barnados.

JAYYUSI, L. (1984) Categorisation and the Moral Order, London, Routledge, Kegan Paul.

JORDAN, B (2000) Social Work and The Third Way: Tough Love as Social Policy, London, Thousand Oaks.

KANIASTY, K. \& NORRIS, F.H. (2000) 'Help-seeking, comfort and receiving social support: The role of ethnicity and context of need.' American Journal of Community Psychology, Vol. 28, pp.545-581.

KEITH-LUCAS, A. (1972) Giving and Taking help. University of North Carolina Press, Chapel Hill N.C.

KELLER, J. \& MCDADE, K. (1997) 'Cultural diversity and help-seeking behaviour: Sources of help and obstacles to support for parents, ' Journal of Multicultural Social Work, Vol 5, pp.63-78. 
LEVENTHAL, J. M. (2001) The prevention of child abuse and neglect: successfully out of the blocks. Child Abuse and Neglect, Vol. 25: pp431-439

MELTZOR, H., BEBBINGTON, P., BRUGHA, T., FARRELL, M., JENKINS, R. \& LEWIS, G. (2000) The reluctance to seek treatment for neurotic disorders,' Journal of Mental Health, vol. 9, pp.319-327.

MORAN, P and GHATE, D (2005) The effectiveness of parenting support. Children and Society, 19, 4, 329336.

NADLER, A. (2006) Intergroup Helping as Status Relations: Effects of Status Stability, Identification, and Type of Help on Receptivity to High-Status Group's Help. Journal of Personality \& Social Psychology, vol. 91 (1), p97-110

OAKLEY, A., RAJAN, L., TURNER, H. (1998) Evaluating parent support initiatives: lessons from two case studies, Health and Social Care in the Community, vol 6, pp.318-330.

PAVULURI, M. N. \& LUK, S. L. (1996) 'Help-seeking for behaviour problems by parents of preschool children: A community study'. Journal of Academic Child and Adolescent Psychiatry, vol. 35(2) ,pp.215221.

PECKOVER, S (2003) "I Could Have Done with Just a Little More Help': An Analysis of Women's HelpSeeking from Health Visitors in the Context of Domestic Violence." Health and Social Care in the Community, vol. 11 (3), pp.275-282.

POLLNER, M. (1974) 'Sociological and Common-Sense Models of the Labelling Process' in Turner, R. (ed.) Ethnomethodology, Harmondsworth: Penguin

PORTWOOD, S.G. (1999) 'Coming to terms with a consensual definition of child maltreatment.' Child Maltreatment, vol. 4 (1), pp.56-68

REDMOND, C., SPOTH, R., \& TRUDEAU, L. (2002) Family- and community-level predictors of parent support seeking. Journal of Community Psychology, Vol. 30: pp.153-157

RICHMOND, M. (1917) Social Diagnosis, New York,: Russell Sage Foundation

ROSE, N. (1990) Governing the Soul: The Shaping of the Private Self, London, Routledge

SACKS, H. (1966) Search for Help: No one to turn to, Berkley, University of California.

SACKS, H. (1984) 'On doing being ordinary'. In: Atkinson, J. M, Heritage, J (editors.) Structures of Social Action: Studies in Conversation Analysis. Cambridge: Cambridge University Press, pp.413-429.

SACKS, H. (1992) Lectures on Conversation. Volumes I and II, Oxford: Blackwell.

SANDERS, R. \& ROACH, G (2007) Closing the gap? The effectiveness of referred access family support services. Child and Family Social Work, vol. 12 (2) pp133-142.

SAYER, A. (2006) Restoring the Moral Dimension: Acknowledging Lay Normativity. Dept. of Sociology, (Lancaster <http:www.comp.lancs.ac.uk/sociology/aperpes/sayer-restoring-moral-dimesion. pdf>)

SHARROCK, W. (1990) On owning knowledge. In: Coulter, J. (Ed.) Ethnomethodological Sociology, Brookfield, VT, Edward Elgar, pp.375-383.

SHEPPARD, M. (2007) How important is Prevention? High Thresholds and Outcomes for Applicants Refused by Children's Services: A Six-Month Follow-Up. The British Journal of Social Work, advance access, published 18. April, doi:10.1093/bjsw/bcm019. pp1-15.

SILVA, E.B. \& SMART, C. (Eds.) (1999) The New Family? London, Sage.

STEPHENS, T. (ed.), (1945) Problem Families: An Experiment in Social Rehabilitation, London, Victor Gollancz.

WITTGENSTEIN, L. (1952) Philosophical Investigations, Oxford: Blackwell.

ZAHNER, G. E. P., PAWELKIEWICZ, W., DEFRANCESCO, J. J. \& ADNOPOZ, J. (1992) 'Children's Mental Health Service Needs and Utilisation Patterns in an Urban Community: An Epidemiologial

Assessment.' Journal of the Academy of Child and Adolescent Psychiatry, vol. 31, pp.951-959. 